Article original

\title{
Frequency of BCR-ABL 1 Fusion Transcripts Variants in Chronic Mye- loid Leukemia Algerian patients
}

\author{
Fréquence des transcrits de fusion $B C R-A B L 1$ chez les patients Algériens atteints \\ de leucémie myéloïde chronique
}

\author{
Mourad NACHI ${ }^{1,2,3}$, Ibtissem KIHEL ${ }^{1,4}$, Badra ENTA-SOLTANE ${ }^{1,5}$, Karima TAIBI ${ }^{6}$, Djaouad.GUELLA ${ }^{1,7}$ Amine \\ ABED ${ }^{1,7}$, Yasmine BOUKHATMP ${ }^{7}$, Mohamed-Amine BEKADJA ${ }^{1,6}$ \\ ${ }^{1}$ Faculty of Medicine, University of Oran 1, Algeria \\ ${ }^{2}$ Department of molecular biology, CHU Oran \\ ${ }^{3}$ Research Laboratory in Pharmaceutical Development, Oran \\ ${ }^{4}$ Laboratory of Biochemistry, CHU Oran \\ ${ }^{5}$ Department of Hematology and Targeted Therapy, Oran \\ ${ }^{6}$ Department of Hematology CHU Oran \\ ${ }^{7}$ Department of Biochemistry, EHU 1st November, Oran
}

Auteur correspondant: mouradnachi1@gmail.com Soumis le 25/03/2020; accepté le 10/05/2020; publié le 21/06/2020

\section{MOTS CLÉS \\ Leucémie Myéloïde Chronique, RT-PCR multiplex, Transcrit BCR-ABL1, transcrits de fusion rares, Co-expres- sion b3a2/b2a2}

\section{Résumé}

Objectif - Dans le contexte de la leucémie myéloïde chronique (LMC), la recherche du transcrit de fusion BCR-ABL1 est devenue indispensable pour confirmer le diagnostic moléculaire. Dans cette étude, nous décrivons les différents types de transcrits de fusion BCR-ABL1 retrouvés chez des patients de l'Ouest algérien atteints de leucémie muéloïde chronique (LMC).

Méthodes - Au total 167 patients suspects de LMC ont été inclus dans cette étude. La recherche qualitative des transcrits de fusion a été réalisée au service de biochimie de l'Etablissement hospitalier et universitaire d'Oran, par la technique d'amplification en chaine par polymérase après rétro-transcription (RT-PCR).

Résultats - Les deux types de transcrits de fusion BCR-ABL1de type majeur Mb3a2 et Mb2a2 étaient présents respectivement dans 59,8 et $36.4 \%$ des cas. Deux patients $(1,8 \%)$ avaient un transcrit atypique rare de type e19a2 et deux autres $(1,8 \%)$, ont co-exprimé les deux types b3a2 et b2a2.

Conclusion - Notre étude a confirmé les données de la littérature en montrant une incidence plus élevée du transcrit majeur. 


\section{KEY WORDS}

Chronic Myeloid Leukemia, multiplex RT-PCR, BCR-ABL1Transcript, rare fusion transcripts, Co-expression b3a2/ b2a2

\section{Introduction}

The chronic myeloid leukemia (CML) is a rare chronic malignant hemopathy belonging to the group of myeloproliferative syndromes [1]. It represents approximately 7 to $15 \%$ of adult leukemia with worldwide incidence varying from 0,6 to 2,8 cases per 100.000 inhabitants [2].

In Algeria, the incidence is lower but it increased from 0,19 per 100.000 inhabitants in 1994 to $0,53 / 100.000$ inhabitants in 2014[3]. On the cytogenetic exam, CML is characterized by presence of an abnormal chromosome in more than $95 \%$ of cases; the Philadelphia chromosome was discovered in the 60's [4]. It is the result of reciprocal translocation between the long arms of chromosomes 9 and 22: $t$ (9-22) (q34; q11), which fuses the gene coding for the tyrosine kinase $c$-abl (cellular homologue of the viral oncogene Abelson ) located on chromosome 9 to the «breakpoint cluster region (BCR)» gene located on chromosome 22. The resulting BCR-ABL1 fusion gene codes for an abnormal chimeric protein BCR-ABL1 of $210 \mathrm{kDa}$ (p210) having a high constitutional tyrosine kinase activity responsible for the leukemic mechanism of CML $[5,6]$.

Depending on the position of the breakpoint on $B C R$ and $A B L$ genes, several chimeric mRNAs can be transcribed. In the context of CML, b2a2 (e13a2) or b3a2 (e14a2) transcripts (cut in Mbcr) are found in more than $95 \%$ of cases. Rarely, the break points interrupting the $B C R$ and $A B L 1$ genes can be in alternative regions leading to very rare and atypical transcripts: e8a2, e6a2, e19a2, e1a3, b2a3, b3a3 and e1a2 [7]. The e1a2 transcript is found especially in acute lymphoblastic leukemias with Philadelphia chromosome (LAL phi +).
The introduction in the 2000's of tyrosine kinase inhibitors (TKI), with imatinib as leader, revolutionized the prognosis of the disease and improved the overall survival of patients [8].

The fundamental criterion for diagnostic confirmation of CML remains the demonstration of the translocation $t(9 ; 22)$ (q34; q11) in cytogenetics, and molecular characterization of the $B C R-A B L 1$ fusion gene. The fusion of the BCR and ABL1 genes is objectified by PCR amplification on a total RNA extract obtained after reverse transcription (RT-PCR). A qualitative reverse transcriptase PCR on peripheral blood cells is mandatory to identify the type of BCR-ABL1 transcripts that can be appropriately followed when assessing response to TKI therapy [9].

The major problem with molecular diagnosis is that some patients can express variant transcripts. It is highly recommended to use multiplex amplification strategies able to amplify most of these transcripts [10,11]. In this study, we present the molecular profile of western Algerian patients with CML.

\section{Material and methods}

This is a descriptive monocentric study with prospective collection involving 167 patients over a period of 6 years (2013-2019). Patients were mainly from Oran and from the other citys of the west Algeria (Mostaganem, Mascara, Sidi Bel Abbes, Ain Temouchent, Relizane, Tiaret and El Bayedh). The study was carried out at the biochemistry department of Oran's university hospital establishment. The study involved all patients over of 18 years old, regardless of sex, admitted for confirmation of diagnosis of CML.

The samples used for the study are whole blood collected 
in tubes with ethylene diamine tetra tripotassium acetate (K3-EDTA) as an anticoagulant. The extraction of ribonucleic acids (total RNA) was carried out on a Maxwell $16 \AA$ automatic extractor (Promega kit). To appreciate the purity of the extracted samples, RNA is quantified by spectrophotometer after a double reading absorbance at $260 \mathrm{~nm}$ and $280 \mathrm{~nm}$.

The qualitative research of the BCR-ABL1 transcript was carried out by reverse transcriptase polymerase chain reaction (RT-PCR) Multiplex technique using the seeplex ${ }^{\text {TM }}$ Leukemia BCR/ABL kit (Seegene, Seoul, Korea). For each amplification, negative and positive controls were tested. The amplified products were separated according to their size by electrophoretic migration on $2 \%$ agarose gel and revealed by ethidium bromide.

The interpretation of the results was made after checking for the presence of ABL1 control gene bands (600 bp) showing good RNA quality, negative and positive control and, in the case of positive samples, a band corresponding to the expected size in the case of positive samples,

a corresponding band to the expected size by comparing to the size marker used: Mb3a2 (476pb), Mb2a2 (401pb) e1a2 (348pb) and c3a2 or e19a2 (micro: 1012 bp) (Figure 1).

\section{Results}

A total of 167 patients were included in our study. The molecular diagnosis of CML was confirmed in 107 patients (64\%) with middle age $47,60 \pm 13$, 76 years and extremes between 19 and 78 years. The sex ratio $(\mathrm{m} / \mathrm{w})$ is 1,05 . However, the molecular study allowed us to exclude the diagnosis of CML in 60 patients (36\%). The molecular study by multiplex RT-PCR has revealed that 103 patients (96\%) had the major type of molecular rearrangement. Two patients expressed a rare and atypical transcript e19a2 $(1,8 \%)$ and two others had a co-expression of b3a2 / b2a2 (1,8\%) (Figure 2). The clinical and epidemiological characteristics and the results of the multiplex RT-PCR of our study group are shown in Table 1.

Fig1.Electrophoretic separation on agarose gel "Seeplex®" according to the size of the fragments.

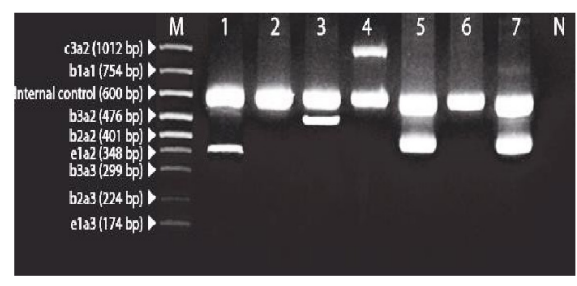

$\mathrm{N}$ : Negative control

1-7 :Samples: 1(e1a2), 2 and 6 negatives. 3

(b3a2), 4 (c3a2 ou e19a2), 5 et 7 (b2a2).

$M$ : Size marker
Table 1. Baseline characteristics of 107 patients with chronic myeloid leukemia

\begin{tabular}{ll}
\multicolumn{2}{c}{ Variable } \\
Gender, N (\%) \\
- Men \\
- Women & $55(51 \%)$ \\
Age & $52(49 \%)$ \\
\hline
\end{tabular}

Median age (range) 48 [19-78]

\begin{tabular}{lr} 
Disease phase, N (\%) & \\
- Chronic & $00(93)$ \\
- Accelerated & $05(05)$ \\
- Blastic & $02(02)$ \\
\hline BCR-ABL1 fusion transcripts, N (\%) \\
\hline Mb3a2 & $64(59.8)$ \\
- Mb2a2 & $39(36.4)$ \\
- e19a2 & $02(1.8)$ \\
- b3a2/b2a2 & $02(1.8)$
\end{tabular}

\begin{tabular}{|c|c|}
\hline \multicolumn{2}{|l|}{ Sokal score, N (\%) } \\
\hline - Low & $30(28)$ \\
\hline - Intermediate & $51(48)$ \\
\hline - High & $26(24)$ \\
\hline \multicolumn{2}{|l|}{ EUTOS score, N (\%) } \\
\hline - Low & $85(79)$ \\
\hline • High & $22(21)$ \\
\hline WBC count, $10^{y} / \mathrm{L}$ median (range) & $141.9[3.4-2210]$ \\
\hline$\underline{\mathrm{Hb}}, \mathrm{g} / \mathrm{dL}$ median (range) & $10[5.3-14]$ \\
\hline PLT count, g/L median (range) & $419[90-710000]$ \\
\hline Myelemia, median (range) & $33.5[0-80]$ \\
\hline Spleen, cm median (range) & $9.5[0-40]$ \\
\hline
\end{tabular}

Fig 2. Multiplex RT-PCR products of patient samples.
A

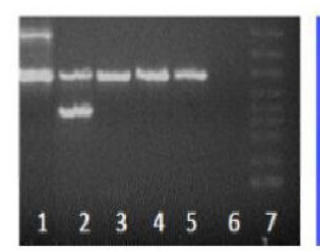

B

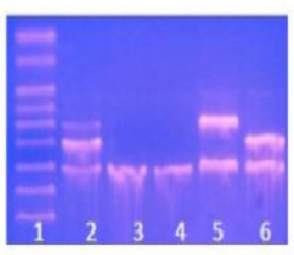

A- 1: e19a2; 2 :b2a2; 3,4,5 : Negative patient; 6: Negative control;7: Size marke

B- 1 : Size marke;2:b3a2/b2a2 ;3 and 4: Negative patient; 5:b2a2; 6:b3a2

JFMO : Vol 4,Numéro 1 (8), Juin 2020527 


\section{Discussion}

In the present study, we choose the Multiplex PCR with commercial kit to do a qualitative research of the different BCR-ABL1 transcripts. This choice was dictated by the great specificity and sensitivity of the kit using dual primer technology $\mathrm{DPO}^{\mathrm{m}}$ (Dual oligo primer or DOP).

Conventional RT-PCR can be used to detect BCR-ABL1 transcripts of $C M L$, however it can give a false negative result for atypical transcript and co-expression complexes, its protocol uses three distinct reactions: the first one for $\mathrm{b} 3 \mathrm{a} 2$ and $\mathrm{b} 2 \mathrm{a} 2$, second one for $\mathrm{e} 1 \mathrm{a} 2$ and finally, the third one for $\mathrm{c} 3 \mathrm{a} 2$ (or e19a2). On the other hand, the multiplex RT-PCR uses in a same reaction several pairs of specific primers, can identify the different variants of BCR-ABL1: Mb2a2, Mb3a2, m e1a2, b1a1, b3a3, e19a2, b2a3, c3a2 and e1a3, with $0.1 \%$ of detection limit. Indeed, several studies explained its interest in the determination of molecular isoforms. Moreover, the Korean study realized on 548 patients had compared the results of the two techniques and had found the same type of transcripts except for a patient detected as an atypical e1a3 transcript type by RT-PCR multiplex but negative by the conventional one [12].

Other studies on different ethnic groups identified atypical BCRABL1 transcripts on different parts of BCR and ABL1 exons such as e1a3, e2a1, e6a2, e8a2, e13a3 (or b2a3) and e14a3 (or b3a3) [13-15]. Other transcripts can be identified such as e12a3, e6a3, e19a3, e20a2 and e20a3 [7]. In the present study, the major transcript was present in $96 \%$ of cases with a higher incidence of the molecular isoform b3a2 than b2a2 $(59,8$ vs $36,4 \%)$. The variable frequencies were reported by several study groups about incidence of transcripts. Indeed, in a meta-analysis study of 26 articles, $22(85 \%)$ had a higher incidence of the b3a2 transcript but in only 4 works, the incidence of b2a2 was higher [16]. In a series of 45503 newly diagnosed CML patients reported from 45 countries, it was found that the proportion of b2a2 and b3a2, including the cases co-expressing b3a2 and b2a2, was $37,9 \%$ and $62,1 \%$, respectively. Other, rare transcripts were reported in 666/34561 patients (1,93\%) [17].

In The Tunisian population study of Bennour et al, similar results were found, with a frequency of b3a2 $(63,63 \%)$ twice more than of b2a2 (36,36\%) [18]. Another Algerian study of 87 patients with CML, had found rates of $54 ; 44,60$ and $1,20 \%$ respectively for the b3a2, b2a2 transcripts and the co-expression b3a2 / b2a2 [19].

In Far and middle Eastern countries (Korea, India, Iran, Syria and Irak population), the frequencies are almost similar with also a higher incidence of b3a2 than b2a2 [12, 20-23]. Similar frequencies had also been found in studies of European populations (Germany and Italy) [24, 25]. Paradoxically, in some populations, the incidence of b2a2 was higher than that of b3a2 with variable frequencies: Syrian population ( 57,1 vs $14,3 \%$ ) [26], Mexican population (48 vs $35 \%$ ) [27], Sudanese population (53,5 vs $41,9 \%$ ) [28], USA population (42 vs $41 \%$ ) [29], and Ecuadorian population ( 95 vs $5 \%, P=0.01$ ) [30]. This could be explicated by the difference of genetic profiles of these populations compared to the others.

The difference in frequency of $\mathrm{b} 3 \mathrm{a} 2$ and $\mathrm{b} 2 \mathrm{a} 2$ rearrangements observed in these different studies could be explained by different factors: geographic and ethnic origin, environmental factors, and the sensitivity detection of the method used. The co-expression b3a2/b2a2 found in our study could be explained by the alternative splicing process.

In Other studies; atypical complex co-expressions were found like those of the Mexican study (e1a2 / b3a2 / b2a2 and e1a2 / b2a2 / e19a2). These complex co-expressions reflect the existence of several leukemic clones [27].

\section{Conclusion}

Our study allowed us, to make the molecular certainty diagnosis of CML. The diagnosis by multiplex gives more informations about variant transcripts, allowing a better choice of the specific primers for the subsequent following up of the molecular response under treatment.

At diagnosis, the determination of the molecular isoform and co-expressions is also clinically interesting to identify the relationships that may exist between the type of the hybrid protein and the phenotypic expression. Moreover, this study will offer possibility to compare, during molecular monitoring, the response to therapy with tyrosine kinase inhibitors function of BCR-ABL1 transcript type.

\section{Conflicts of interest: None.}

\section{References}

[1]. Arber DA, Orazi A, Hasserjian R, Thiele J, Borowitz MJ, Le Beau MM, et al. The 2016 revision to the World Health Organization classification of myeloid neoplasms and acute leukemia. Blood. 2016;127(20):2391-405. [2].Rohrbacher M, Hasford J. Epidemiology and Etiology of Chronic Myeloid Leukemia. Neoplastic Diseases of the Blood: Springer; 2018. p. 9-17. [3].Djouadi K AN, Harieche F, et al. Approche épidémiologique de la leucémie myéloïde chronique Etude Algéro-Tunisienne à propos de 1349 cas sur 05 ans (2010 à 2014). Revue Algérienne d’Hématologie. 2017;Nํ13 \& 14, Décembre 2017. 
[4].PC IN, Hungerford D. A minute chromosome in human chronic granulocytic leukemia. Science. 1960;132:1497-9.

[5]. Rowley JD. A new consistent chromosomal abnormality in chronic myelogenous leukaemia identified by quinacrine fluorescence and Giemsa staining. Nature. 1973;243(5405):290-3.

[6].Heisterkamp N, Stephenson JR, Groffen J, Hansen PF, de Klein A, Bartram CR, et al. Localization of the c-abl oncogene adjacent to a translocation break point in chronic myelocytic leukaemia. Nature. 1983;306(5940):239-42.

[7]. Burmeister T, Reinhardt R. A multiplex PCR for improved detection of typical and atypical BCR-ABL fusion transcripts. Leukemia research. 2008;32(4):579-85.

[8]. Kantarjian H, O'Brien S, Jabbour E, Garcia-Manero G, Quintas-Cardama A, Shan J, et al. Improved survival in chronic myeloid leukemia since the introduction of imatinib therapy: a single-institution historical experience. Blood, The Journal of the American Society of Hematology. 2012;119(9):1981-7.

[9]. Hochhaus A, Baccarani M, Silver R, Schiffer C, Apperley J, Cervantes $\mathrm{F}$, et al. European LeukemiaNet 2020 recommendations for treating chronic myeloid leukemia. Leukemia. 2020:1-19.

[10].Cayuela J-M, Huguet F. Chronic myeloid leukemia (CML) diagnosis in 2012. Oncologie. 2012;14(10-11):561-8.

[11].Gendron N, Belhouachi N, Morel V, Azgui Z, Maloum K, Nguyen-Khac $\mathrm{F}$, et al., editors. Leucémie myéloïde chronique avec transcrit de fusion variant BCR-ABL1 e19a2: intérêt de l'identification moléculaire au diagnostic pour le suivi de la maladie résiduelle. Annales de Biologie Clinique; 2014.

[12].Goh H-G, Hwang J-Y, Kim S-H, Lee Y-H, Kim Y-L, Kim D-W. Comprehensive analysis of BCR-ABL transcript types in Korean CML patients using a newly developed multiplex RT-PCR. Translational Research. 2006;148(5):249-56.

[13].Cayuela J-M, Rousselot P, Nicolini F, Espinouse D, Ollagnier C, BuiThi $M$, et al. Identification of a rare e8a2 BCR-ABL fusion gene in three novel chronic myeloid leukemia patients treated with imatinib. Leukemia. 2005;19(12):2334-6.

[14].Jinawath N, Norris-Kirby A, Smith BD, Gocke CD, Batista DA, Griffin CA, et al. A rare e14a3 (b3a3) BCR-ABL fusion transcript in chronic myeloid leukemia: diagnostic challenges in clinical laboratory practice. The Journal of Molecular Diagnostics. 2009;11(4):359-63.

[15]. Huet S, Dulucq S, Chauveau A, Menard A, Chomel JC, Maisonneuve $\mathrm{H}$, et al. Molecular characterization and follow-up of five CML patients with new BCR-ABL 1 fusion transcripts. Genes, Chromosomes and Cancer. 2015;54(10):595-605.

[16]. Ercaliskan A, Eskazan AE. The impact of BCR-ABL1 transcript type on tyrosine kinase inhibitor responses and outcomes in patients with chronic myeloid leukemia. Cancer. 2018;124(19):3806-18.

[17].Baccarani M, Castagnetti F, Gugliotta G, Rosti G, Soverini S, Albeer $A$, et al. The proportion of different BCR-ABL1 transcript types in chronic myeloid leukemia. An international overview. Leukemia. 2019;33(5):1173-83.
[18].Bennour A, Ouahchi I, Achour B, Zaier M, Youssef YB, Khelif A, et al. Analysis of the clinico-hematological relevance of the breakpoint location within $M-B C R$ in chronic myeloid leukemia. Medical oncology. 2013;30(1):348.

[19].Harieche F. PCR quantitative en temps réel : application au diagnostic et à l'étude de la maladie résiduelle dans les leucémies myéloïdes chroniques [Thèse]. Université d'Alger 2008.

[20].Yaghmaei M, Ghafari S, Ghavamzadeh A, Ali MK, Jahani M, Mousavi $S$, et al. Frequency of BCR-ABL fusion transcripts in Iranian patients with chronic myeloid leukemia. 2008.

[21]. Al-Achkar W, Moassass F, Youssef N, Wafa A. Correlation of p210 $B C R-A B L$ transcript variants with clinical, parameters and disease outcome in 45 chronic myeloid leukemia patients. J BUON. 2016;21(2):444-9. [22].Khazaal MS, Hamdan FB, Al-Mayah QS. Association of BCR/ABL transcript variants with different blood parameters and demographic features in Iraqi chronic myeloid leukemia patients. Molecular genetics \& genomic medicine. 2019;7(8):e809.

[23].Kagita S, Mamidi TK, Digumarti L, Gundeti S, Digumarti R. Assessment of BCR-ABL1 fusion transcripts and their association with response to imatinib treatment in chronic myeloid leukemia patients. Indian Journal of Medical and Paediatric Oncology. 2018;39(2):165.

[24]. Hanfstein B, Lauseker M, Hehlmann R, Saussele S, Erben P, Dietz $C$, et al. Distinct characteristics of e13a2 versus e14a2 BCR-ABL1 driven chronic myeloid leukemia under first-line therapy with imatinib. haematologica. 2014;99(9):1441-7.

[25].Castagnetti F, Gugliotta G, Breccia M, lurlo A, Levato L, Albano F, et al. The BCR-ABL1 transcript type influences response and outcome in $\mathrm{P}$ hiladelphia chromosome-positive chronic myeloid leukemia patients treated frontline with imatinib. American journal of hematology. 2017;92(8):797-805.

[26].Farhat-Maghribi S, Habbal W, Monem F. Frequency of BCR-ABL transcript types in Syrian CML patients. Journal of oncology. 2016;2016.

[27].Arana-Trejo R, Sanchez ER, Ignacio-Ibarra G, De La Fuente EB, Garces 0, Morales EG, et al. BCR/ABL p210, p190 and p230 fusion genes in 250 Mexican patients with chronic myeloid leukaemia (CML). Clinical \& Laboratory Haematology. 2002;24(3):145-50.

[28].Osman E-Al, Hamad K, Elmula IMF, Ibrahim ME. Frequencies of BCRABL1 fusion transcripts among Sudanese chronic myeloid leukaemia patients. Genetics and molecular biology. 2010;33(2):229-31.

[29].Jain P, Kantarjian H, Patel KP, Gonzalez GN, Luthra R, Shamanna RK, et al. Impact of BCR-ABL transcript type on outcome in patients with chronic-phase CML treated with tyrosine kinase inhibitors. Blood, The Journal of the American Society of Hematology. 2016;127(10):1269-75. [30].Paz-y-Miño C, Burgos R, Morillo SA, Santos JC, Fiallo BF, Leone PE. $B C R-A B L$ rearrangement frequencies in chronic myeloid leukemia and acute lymphoblastic leukemia in Ecuador, South America. Cancer genetics and cytogenetics. 2002;132(1):65-7. 
